and bronchi. Thorax. 1972;27(2):188-194.

3. van Roozendaal LM, van Gool MH, Sprooten RTM, et al. Surgical treatment of bronchial rupture in blunt chest trauma: a review of literature. J Thorac Dis. 2018;10(9):5576-5583. doi:10.21037/jtd.2018.08.22

4. Hartley $C_{,}$Morritt GN. Bronchial rupture secondary to blunt chest trauma. Thorax. 1993;48(2):183-184.

5. Rossbach MM, Johnson SB, Gomez MA, Sako EY, Miller OL, Calhoon JH. Management of major tracheobronchial injuries: a 28-year experience. Ann Thorac Surg. 1998;65(1):182-186. doi:10.1016/s0003-4975(97)01001-1

6. Pulle MV, Asaf BB, Puri HV, Bangeria S, Bishnoi S, Kumar A. Factors determining surgical outcome after bronchial re-implantation for traumatic main bronchus transection. Lung India.
2021;38(2):128.

doi:10.4103/lungindia.lungindia 30620

7. Ozdulger A, Cetin G, Gulhan SE, Topcu S, Tastepe I, Kaya S. A review of 24 patients with bronchial ruptures: is delay in diagnosis more common in children? Eur J Cardiothorac Surg. 2003;23(3):379-383. doi:10.1016/s1010 7940(02)00754-6

8. Díaz C, Carvajal DF, Morales EI, Sangiovanni S, Fernández-Trujillo L. Right main bronchus rupture associated with blunt chest trauma: a case report. Int J Emerg Med. 2019;12. doi:10.1186/s12245-019-0258-3

9. Wang H-LC, How C-H, Lin H-F, Lee J-M, Traumatic left main bronchial rupture: delayed but successful outcome of robotic-assisted reconstruction. Respirol Case Rep. 2018;6(1):e00278. doi:10.1002/rcr2.278

\title{
ĐẶC ĐIỂM MÔ BÊ̂NH HỌC, GIÁ TRI ĐO ĐIỆN THẾ NIÊM MẠC THƯ⿱C QUẢN VÀ KẾT QUẢ NổI SOI Ở BÊ̂NH NHÂN CÓ TRIỆU CHỨNG TRÀO NGƯợC DẠ DÀY THỰC QUẢN
}

\section{TÓM TẮT}

Nghiên cứu mô tả nhằm đánh giá mối liên quan đăc điểm mô bênh hoc, giá tri đo điên thế niêm mac thực quản (MA) và kết quả nội soi ở bệnh nhân có triệu chứng trào ngược dạ dày thực quản. Nghiên cứu được tiến hành từ 9/2020 đến 12/2020 tại Viện Nghiên cứu và Đào tao Tiêu hóa, Gan mât - Phòng khám Hoàng Long trển các đối tượng có biểu hiện trào ngước da dày thức quản, đước tiến hành nội soi đường tiểu hóa trên tiền mê và tiển hành đo điện thế niêm mac thực quản và lấy sinh thiết mô bênh học trong quá trình nội soi. 30 bệnh nhân (14 nam) được thu tuyển, tuổi trung bình 42,1 (năm). Tỉ lê viêm thực quản trào ngược (VTQTN) trên nội soi là $70 \%$, chủ yếu là viêm thức quản đô $\mathrm{A}$ theo Los Angeles, Barrett thực quản chiếm $10 \%$. Các đặc điểm trên mô bệnh học theo thang điểm Esohisto và giá trị MA tại vị trí 5 $\mathrm{cm}$ và $15 \mathrm{~cm}$ trên đường $Z$ không có sự khác biệt có ý nghĩa thống kê giữa hai nhóm có và không có VंTQTN trên nôi soi. Giá tri $M A$ tai vi trí $5 \mathrm{~cm}$ và $15 \mathrm{~cm}$ trên đường $Z$ cũng không có sự khác biệt giữa nhóm có và không có viêm thực quản trên mô bênh hoc.

Từ khóa: Trào ngược dạ dày thực quản, điện thế niêm mạc thực quản, mổ bệnh học.

\section{SUMMARY \\ HISTOPATHOLOGY CHARACTERISTICS,}

${ }^{1}$ Trường Đại hoc Y Hà Nội

2Trung tâm Nội soi, Bệnh viện Đai học Y Hà Nội

${ }^{3}$ Viện Nghiên cúu và Đào tạo Tiểu hóa, Gan mật

Chịu trách nhiệm chính: Đào Việt Hằng

Email: hangdao.fsh@gmail.com

Ngày nhân bài: 6.4.2021

Ngày phản biên khoa hoc: 26.5.2021

Ngày duyệt bài: 7.6.2021
Đào Việt Hằng1,2,3, Đào Văn Long1,2,3

MUCOSAL ADMITTANCE VALUES AND ENDOSCOPY FINDINGS IN PATIENTS WITH GASTROESOPHAGEAL REFLUX SYMPTOMS

The study was conducted to evaluate the relationship between histopathological results, mucosal admittance (MA) value and endoscopic results in patients with gastroesophageal reflux symptoms. We performed this study between 9/2020 and $12 / 2020$ at the Institute of Gastroenterology and Hepatology - Hoang Long Clinic among patients who had gastroesophageal reflux symptoms, underwent endoscopy simultaneously with tissue conductance measure and histopathology with esophageal mucosal samples. 30 patients (14 males) were recruited, mean age was 42.1 (years). The prevalence of reflux esophagitis on endoscopy was $70 \%$, predominantly Los Angeles grade A, Barrett's esophagus was seen in $10 \%$ of patients. Histopathological patterns based on Esohisto criteria and MA values at $5 \mathrm{~cm}$ and $15 \mathrm{~cm}$ above $Z$ line were not significantly different between patients with and without reflux esophagitis on endoscopy. MA values at $5 \mathrm{~cm}$ and $15 \mathrm{~cm}$ above $Z$ line were also not significantly different between patients with and without esophagitits on histopathology.

Keywords: Gastroesophageal Reflux Disease, Mucosal Admittance, TCM (Tissue Conductance Meter)

\section{I. ĐĂT VẤN ĐỀ}

Trào ngược dạ dày thực quản (Gastroesophageal reflux disease - GERD) là tình trangdodịch dạ dày trào lên thực quản gây ra các triệu chứng khó chịu và/hoặc biến chứng. ${ }^{1}$ Các phương pháp chẩn đoán GERD hiện nay bao gồm áp dụng bộ câu hỏi lâm sàng, điểu trị thử với thuốc ức chể bơm proton (PPI), nội 
soi dạ dày thực quản, sinh thiết niêm mạc thực quản và đo $\mathrm{pH}+/-$ trở kháng 24 giờ thực quản. ${ }^{2}$ Ưu điểm và nhược điểm của mối phướng pháp được đưa ra chi tiết trong đồng thuận Lyon (2018): Bô câu hỏi lâm sàng và điều trị thử với PPI tuy dễ áp dụng, nhưng độ nhạy và độ đặc hiệu thấp, nội soi dạ dày thực quản là phương pháp xâm lẩn thường được sử dụng trên lâm sàng nhưng cũng có đến $2 / 3$ người có triệu chứng GERD có hình ảnh nội soi thực quản bình thường; đo $\mathrm{pH}+/-$ trở kháng 24 giớ hiện là phương pháp có độ nhạy, độ đặc hiệu cao nhất trong chẩn đoán GERD, tuy nhiên đây là kĩ thuật xâm lấn, cần nhiều thời gian thực hiện và phẩn tích kết quả, có thể gây một số khó chịu cho người bệnh trong quá trình đeo máy, chi phí dịch vụ cao. ${ }^{2}$ Theo đồng thuận từ các nhà giải phẫu bệnh, sinh thiết niêm mạc thực quản và áp dụng thang điểm Esohisto trong chẩn đoán GERD là phương pháp hữu ích, đặc biệt với nhóm bệnh nhân không có tổn thương trển nội soi(NERD). ${ }^{3} Đ o$ điện thế niêm mạc (TCM) cũng là một kỹ thuât được tiến hành trong quá trình nôi soiđể đánh giá thay đổi tính dẫn điện của niểm mạc thực quản. Ở bệnh nhân GERD, giá trị trở kháng nền của niêm mạc thực quản có tương quan nghịch với thời gian niêm mạc tiếp xúc acid, một trong những tiêu chuẩn chẩn đoán xác định trền đo $\mathrm{pH}$ thực quản 24 giờ. ${ }^{4}$ Do vậy TCM được kì vọng giúp dự đoán những thay đổi về mặt vi thể của niêm mạc thực quản khi chưa có tổn thương viêm thực quản quan sát được trên nội soi. 5,6

Đo điện thế niêm mạc thực quản trong chẩn đoán GERD còn tương đối mới ở Viêt Nam và chưa có dữ liệu đối chiếu với kết quả mô bệnh học. Do đó, chúng tôi tiến hành nghiên cứu này nhằm đánh giá mối liên quan giữa đặc điểm nội soi, kết quả mô bệnh học và kết quả đo điện thế niêm mạc thực quản trên bệnh nhân có triệu chứng trào ngược dạ dày thực quản.

\section{II. ĐỐI TƯỢNG VÀ PHƯƠNG PHÁP NGHIÊN CỨU}

Nghiên cứu mô tả cắt ngang từ tháng 9/2020 đến tháng 12/2020 trên 30 bệnh nhân trên 18 tuổi đến khám tại Phòng khám đa khoa Hoàng Long. Tiêu chuẩn lựa chọn bao gồm: (1) có triệu chứng trào ngược da dày thực quản, (2) được tiến hành nội soi đường tiêu hóa trên tiên mề, đo điện thế niêm mạc thực quản và được tiến hành sinh thiết niêm mạc thực quản trong quá trình nội soi.

Các triệu chứng trào ngược dạ dày thực quản bao gồm trào ngược hoặc nóng rát sau xương ức; các triệu chứng nghi ngờ trào ngược ngoài thực quản như ho, rát họng kéo dài đã được ngoại trừ bệnh lý hô hấp, đau ngực không do tim đã được khám chuyên khoa tim mạch. Kĩ thuật đo pH-trở kháng thực quản 24 giờ tiến hành khi bệnh nhân ngừng sử dụng thuốc ức chế bơm proton tối thiểu 5 ngày.

Đo điện thế niêm mạc thực quản (TCM). Kỹ thuật sử dụng một catheter nhỏ đường kính $1,9 \mathrm{~mm}$ cho qua kênh sinh thiết nội soi tiếp xúc với niêm mạc thực quản để đo giá trị điện thế của niêm mạc (MA). Đầu catheter tiếp xúc với niêm mạc thực quản mối lần đo từ 2-3 giây và được đo 5 îân mỗi vị trí: cách vùng nối tâm vị $5 \mathrm{~cm}$ (đoạn xa thực quản) và $15 \mathrm{~cm}$ (đoạn giữa thực quản). Các giá trị sẽ được ghi lại vào hệ thống phần mềm kết nối với hệ thống máy đo và catheter.

Mô bệnh học (MBH). Các bệnh nhân được nội soi và sinh thiết 2 mảnh niêm mạc thực quản tại vị trí $5 \mathrm{~cm}$ trên đường $Z$. Tiêu bản được nhuộm hematoxyline eosin và phân loại mức độ nặng theothang điểmEsohisto bao gồm các yếu tổ: mức độ tăng sản lớp đáy, độ giãn của nhú niêm mạc, độ giãn khoảng gian bào và thâm nhập tế bào viêm (bạch cầu ưa acid, bạch cầu trung tính, bạch câu đơn nhân) trong biểu mô. Mỗi yếu tố được đánh giá trên thang điểm từ 0 đến 2, điểm mức độ viêm thực quản được tính bằng tổng điểm của các yếu tố chia cho tổng số yếu tố đánh giá. Điểm $0-0,25$ là bình thường, $0,5-0,75$ là viêm thực quản nhẹ, $\geq 1$ là viêm thực quản nặng.

Bảng 1: Tiêu chuẩn mô bênh hơc theo Esohisto

\begin{tabular}{|c|c|c|c|}
\hline \multirow{2}{*}{ Đặc điểm } & \multirow{2}{*}{\multicolumn{3}{|c|}{ Điếm }} \\
\hline & & & \\
\hline Tănq sản lớp & & $\frac{1}{15-30}$ & 20 um \\
\hline đáy & $<15 \mu \mathrm{m}$ & $\mu \mathrm{m}$ & $>30 \mu \mathrm{m}$ \\
\hline $\begin{array}{l}\text { Độ giãn nhú } \\
\text { niêm mạc }\end{array}$ & $<50 \%$ & $50-75 \%$ & $>75 \%$ \\
\hline $\begin{array}{l}\text { Độ giãn khoảng } \\
\text { gian bào }\end{array}$ & Không giãn & \begin{tabular}{|l|} 
Giãn \\
nhẹ
\end{tabular} & $\begin{array}{l}\text { Giãn } \\
\text { rộng }\end{array}$ \\
\hline \multicolumn{4}{|c|}{ Thâm nhập thế bào viêm } \\
\hline $\begin{array}{c}\text { Bạch cầu ưa } \\
\text { axit }\end{array}$ & Không có & $\begin{array}{c}1-2 \text { tế } \\
\text { bào }\end{array}$ & $\begin{array}{l}>2 \text { tế } \\
\text { bào }\end{array}$ \\
\hline $\begin{array}{l}\text { Bạch câu trung } \\
\text { tính }\end{array}$ & Không có & $\begin{array}{c}1-2 \text { tế } \\
\text { bào }\end{array}$ & $\begin{array}{l}>2 \text { tế } \\
\text { bào }\end{array}$ \\
\hline $\begin{array}{l}\text { Bạch cầu đơn } \\
\text { nhân }\end{array}$ & $<10$ tế bào & $\begin{array}{l}10-30 \\
\text { tế bào }\end{array}$ & $\begin{array}{l}>30 \text { tế } \\
\text { bào }\end{array}$ \\
\hline
\end{tabular}

Xử lý số liệu. Số liệu được nhập phân tích bằng phần mềm SPSS 2.0. Các biển định tính được trình bày dưới dạng số đếm và tỉ lệ phần trăm (\%). Các biện định lượng sẽ được biểu diễn dưới dạng trung bình ( \pm phương sai) cho phân bố chuẩn, hoặc trung vị (khoảng tử phân vị) cho phân bố không chuẩn. 


\section{KẾT QUẢ NGHIÊN CứU}

Trong 30 bệnh nhân thu tuyển, nam giới chiếm 46,7\%, tuổi trung bình là 42,1 (min - max: 26-66). Các triệu lâm sàng thường gặp ở nhóm bệnh nhân là trào ngược $(70 \%)$, ợ hơi $(63,3 \%)$, nóng rát sau xương ức (40\%), đau thượng vị (40\%), đầy bụng (40\%). Điểm FSSG, GERDQ trung bình lần lượt là 10,3 và 6,0 . Tỉ lệ điểm FSSG $\geq 8$ và $G E R D Q \geq 8$ lần lượt là $63,3 \%$ và $36,7 \%$.
Trên nội soi dạ dày thực quản, $70 \%$ bệnh nhân có tổn thương viêm thực quản trào ngược (VTQTN), chủ yếu là độ $A(63,4 \%)$. Tỉ lệ VTQTN độ $B, C$ và $D$ lần lượt là $3,3 \%, 3,3 \%$ và $0 \%$. Tỉ lệ bểnh nhân có tổn thương Barret thực quản là $10 \%$, và tất cả đều là Barrett thực quản đoạn ngắn.

Trên mô bệnh học, gần $40 \%$ bệnh nhẩn có kết luận viêm thực quản. Kết quả của từng đặc điểm trền mô bệnh học được mô tả trong bảng 2 .

Bảng 2: Đặc điểm mô bệnh học và giá trị MA theo phân nhóm tổn thương trên nội soi

\begin{tabular}{|c|c|c|c|c|}
\hline Đặc điểm & $\begin{array}{c}\text { Chung } \\
(n=30)\end{array}$ & $\begin{array}{c}\text { VTQTN } \\
(\mathrm{n}=\mathbf{2 1})\end{array}$ & $\begin{array}{c}\text { Không VTQTN } \\
(n=9)\end{array}$ & $\mathbf{p}$ \\
\hline \multicolumn{5}{|c|}{ Đặc điếm mô bệnh học, n (\%) } \\
\hline $\begin{array}{c}\text { Tăng sản lớp đáy: }<15 \% \\
15-30 \% \\
>30 \%\end{array}$ & $\begin{array}{c}24(80,0) \\
6(20,0) \\
0(0)\end{array}$ & $\begin{array}{c}17(70,8) \\
4(66,7) \\
0(0)\end{array}$ & $\begin{array}{c}7(29,2) \\
2(33,3) \\
0(0)\end{array}$ & 0,840 \\
\hline $\begin{array}{r}\text { Giãn nhú niêm mạc: }<50 \% \\
50-75 \% \\
>75 \%\end{array}$ & $\begin{array}{c}17(56,7) \\
11(36,7) \\
2(6,6)\end{array}$ & $\begin{array}{l}11(64,7) \\
8(72,7) \\
2(100)\end{array}$ & $\begin{array}{c}6(35,3) \\
3(27,3) \\
0(0)\end{array}$ & 0,647 \\
\hline Có giãn khoảng gian bào & $4(13,3)$ & $1(25,0)$ & $3(75,0)$ & $(*)$ \\
\hline $\begin{array}{c}\text { Có thâm nhập tế bào viêm } \\
B C \text { ưa axit } \\
B C \text { trung tính } \\
B C \text { đơn nhân }\end{array}$ & $\begin{array}{c}10(33,3) \\
3(10) \\
5(16,7) \\
7(23,3)\end{array}$ & $\begin{array}{l}1(33,3) \\
2(40,0) \\
5(71,4)\end{array}$ & $\begin{array}{l}2(66,7) \\
3(60,0) \\
2(28,6)\end{array}$ & $(*)$ \\
\hline
\end{tabular}

Đặc điếm đo TCM, trung vị (khoảng tứ phân vị)

\begin{tabular}{|c|c|c|c|c|}
\hline MA- $5 \mathrm{~cm}(\Omega)$ & $42,0(21,0-63,1)$ & $50,5(23,9-63,7)$ & $30,5(19,7-60,3)$ & 0,512 \\
\hline MA- $15 \mathrm{~cm}(\Omega)$ & $41,8(30,8-69,8)$ & $43,6(34,7-73,2)$ & $28,1(12,4-68,0)$ & 0,164 \\
\hline
\end{tabular}

VTQTN- Viêm thực quản trào ngược, MA- giá trị điện thế niêm mạc thực quản, $\left(^{*}\right)$ không kiếm định

Bảng 3 so sánh giá trị điện thế niêm mạc (MA) tại hai vị trí 5 và $15 \mathrm{~cm}$ trên đường $Z$ giữa nhóm có và không có viêm thực quản được chẩn đoán trên mô bệnh học. Giá trị MA trung vị tại 2 vị trí không có sự khác biệt có ý nghĩa thống kê giữa hai nhóm.

Bảng 3: Giá trị MA của hai nhóm phân loại theo thang điểm Esohisto trên MBH

\begin{tabular}{|c|c|c|c|}
\hline Đặc điểm & $\begin{array}{c}\text { VTQ trên mố } \\
\text { bệ̂nh hơc } \\
\text { (n= 1i) }\end{array}$ & $\begin{array}{c}\text { Không VTQ trên } \\
\text { mô beênh học } \\
\text { (n= 19) }\end{array}$ & p \\
\hline MA-5 cm, trung vị (khoảng tứ phân vị) $(\Omega)$ & $39,5(12,6-67,5)$ & $44,6(27,4-59,7)$ & 0,735 \\
\hline MA-15 cm, trung vị (khoảng tứ phân vị) $(\Omega)$ & $37,7(11,2-76,8)$ & $48,2(31,7-67,3)$ & 0,445 \\
\hline \multicolumn{2}{|c|}{ VTQ- Viêm thực quản, MA- giá trị điện thế niêm mạc thực quăn } \\
\hline
\end{tabular}

\section{BÀN LUÂ̂N}

Nghiên cứu chúng tôi bước đầu tìm hiểu mối liên quan giữa kết quả nội soi, MBH và giá trị MA trên những bệnh nhân có triệu chứng trào ngược dạ dày thực quản.

Kết quả nghiên cứu ghi nhận gần $40 \%$ bệnh nhân có biểu hiện trào ngược dạ dày thực quản có viêm thực quản trên kết quả MBH trong khi tỉ lệ VTQTN trên nội soi là $70 \%$.Nghiên cứu của chúng tôi áp dụng thang điểm Esohisto bao gồm nhiều yếu tố để xác định tình trạng viêm thực quản trên mô bệnh học: tình trạng quá sản lớp đáy, giãn nhú niêm mạc biểu mô, giãn khoảng gian bào và thâm nhập của tế bào viêm. Sự không phù hợp giữa kểt quả nội soi và $\mathrm{MBH}$ gợi ý cần thêm nhiều nghiên cứu để chứng minh khả năng ứng dụng và giá trị chẩn đoán của thang điểm Esohisto tại Việt Nam, đặc biệt là đối chiếu với tiêu chuẩn vàng là đo $\mathrm{pH}$ trở kháng 24 giờ.

Các đặc điểm trên MBHtrong nghiên cứu này ghi nhận không có sự khác biệt giữa hai nhóm có và không có VTQTNN trên nội soi. Theo một nghiên cứu của Ismail-Beigi, quá sản lớp đáy và giãn nhú niêm mạc biểu mô là hai thay đổi mô bệnh học chính ở các bênh nhân GERD, tuy nhiên độ nhạy và độ đặc hiệu trong chẩn đoán của hai yếu tố trên còn thấp. ${ }^{7}$ Một nghiên cứu khác của Zhou LY và cộng sự sử dụng độ giãn khoảng gian bào (DIS) là tiêu chuẩn trong chẩn đoán GERD ghi nhận độ nhạy và độ đặc hiệu của 
phương pháp là $62,1 \%$ và $56,1 \%{ }^{8}$ Tuy nhiên, trong nghiên cứu chúng tôi chỉ ghi nhận chỉ có 4/30 bệnh nhân có giãn khoảng gian bào.

Trung vị giá trị MA tại vị trí $5 \mathrm{~cm}$ và $15 \mathrm{~cm}$ trên đường $Z$ cao hơn ở nhóm VTQTN so với nhóm không VTQTN trên nội soi, tuy nhiên sự khác biệt có ý nghĩa thống kê. Các nghiên cứu trước đầy đã chỉ ra rằng giá trị MA cao hơn ở các bệnh nhân có VTQTN so với nhóm trào ngược không có VTQTN và cao hơn nhóm chứng khỏe manh. ${ }^{4} \mathrm{Nghiên}$ cứu của Matsumura cho thấy đo TCM có giá trị chẩn đoán phân biệt GERD và nóng rát chức năng tương tự như khi sử dụng phương pháp đo pH trở kháng 24 giờ. ${ }^{4}$

Điểm hạn chế trong nghiên cứu của chúng tôi đó là cõ mẫu còn nhỏ, chưa đối chiếu được với tiêu chuẩn vàng là đo $\mathrm{pH}$-trở kháng thực quản 24 giờ cũng như không thu tuyển được nhóm bệnh nhân viêm thực quản trên nội soi mức độ nặng Los Angeles từ độ $C$ trở lên để so sánh. Đây là nghiên cứu bước đầu do vậy giá trị của kĩ thuật TCM và $\mathrm{MBH}$ trong chẩn đoán GERD cần được đánh giá thêm trong các nghiên cứu tương lai với cõ̃ mẫu lớn hơn và có tiêu chuẩn vàng đối chiếu.

\section{KẾT LUẬN}

Nghiên cứu chúng tôi không ghi nhận sự khác biệt về các đặc điểm trên mô bênh học và đo điện thế niêm mạc thực quản giữa nhóm có và không có viêm thực quản trên nội soi, cũng như không có sự khác biệt về giá trị điện thế niêm mạc thực quản giữa nhóm có và khổng có viêm thực quản trên mô bênh học.

Lời cảm ơn. Nghiên cứu nằm trong đề tài cấp nhà nước của Bộ Khoa học và Công nghệ "Nghiên cứu đánh giá rối loạn vận động và bài tiết một số bệnh lý dạ dày, thực quản" mã số ĐTĐLCN.04/20.

\section{TÀI LIÊU THAM KHẢO}

1. Vakil N, van Zanten SV, Kahrilas P, Dent J, Jones R. The Montreal definition and classification of gastroesophageal reflux disease: a global evidence-based consensus. The American journal of gastroenterology. 2006;101(8):1900-1920; quiz 1943.

2. Gyawali CP, Kahrilas PJ, Savarino E, et al. Modern diagnosis of GERD: the Lyon Consensus. Gut. 2018;67(7):1351-1362.

3. Fiocca $R$, Mastracci $L$, Riddell $R$, et al. Development of consensus guidelines for the histologic recognition of microscopic esophagitis in patients with gastroesophageal reflux disease: the Esohisto project. Human pathology. 2010; 41(2): 223-231.

4. Matsumura $T$, Ishigami $H$, Fujie $M$, et al. Endoscopic-Guided Measurement of Mucosal Admittance can Discriminate Gastroesophageal Reflux Disease from Functional Heartburn. Clin Transl Gastroenterol. 2017;8(6):e94.

5. Farre $R$, Blondeau $K$, Clement $D$, et al. Evaluation of oesophageal mucosa integrity by the intraluminal impedance technique. Gut. 2011;60(7):885-892.

6. Kessing BF, Bredenoord AJ, Weijenborg PW, Hemmink GJ, Loots CM, Smout AJ. Esophageal acid exposure decreases intraluminal baseline impedance levels. Am J Gastroenterol. 2011;106(12):2093-2097.

7. Ismail-Beigi F, Horton PF, Pope CE, 2nd. Histological consequences of gastroesophageal reflux in man. Gastroenterology. 1970;58(2):163-174.

8. Zhou LY, Wang Y, Lu JJ, et al. Accuracy of diagnosing gastroesophageal reflux disease by GerdQ, esophageal impedance monitoring and histology. J Dig Dis. 2014;15(5):230-238.

\section{NGHIÊN CỨU GIÁ TRI THANG ĐIỂM VIÊM PHỔI SEOUL TRÊN BÊ̂NH NHÂN VIÊM PHỔI THỨ PHÁT SAU ĐộT QUỴ NÃO CẤP TẠI TRUNG TÂM ĐộT QUỴ PHÚ THọ}

\section{TÓM TẮT}

Mục tiêu: Khảo sát giá trị thang điểm Viêm phổi Soeul ở bệnh nhân đột quy não trong giai đoạn cấp. Đối tượng và phương pháp nghiên cứu: Gồm 65 bệnh nhân đột quỵ não lần đâu được nhập viện điều

*Sở Y tế Phú Tho

**Bênh viện Đa khoa tỉnh Phú Tho

Chịu trách nhiệm chính: Nguyễn Huy Ngọc

Email: ngohuynguyen8888@gmail.com

Ngày nhận bài: 7.4.2021

Ngày phản biện khoa học: 26.5.2021

Ngày duyệt bài: 8.6 .2021

\section{Nguyễn Huy Ngọc*, Nguyễn Quang Ân**}

trị nội trú tại Trung tâm Đột quy - Bênh viện tỉnh Phú Tho từ tháng 11 năm 2020 đến tháng 3 năm 2021. Chẩn đoán viêm phổi bênh viên theo Hướng dẫn chẩn đoán và điều trị bệnh hô hấp do Bộ $Y$ Tế ban hành năm 2012. Nghiên cứu được tiến hà̀nh theo phương pháp tiến cứu, thống kê mồ tả. Kết quả: Tuổi trung bình là $62,0 \pm 11,5$, tỉ lê nam/ nữ: $2 / 1$, điểm NIHSS trung bình $8,2 \pm 6,5$ và bệnh nhân có thông khí cơ hoc chiếm 7,3\%. Tí lê viêm phổi bênh viện là 13,5\%. Ở bệnh nhân ở thể đột quy chảy máu, có thông khí cơ học, tình trạng rối loạn ý thức nặng (Glasgow < 9), mức độ đột quy nặng (NIHSS $\geq 15$ ) thì có tỉ lệ viêm phổi cao hớn hẳn với $\mathrm{p}<0,001$; không có mối liên quan giữa tuổi, giới và mức huyết áp với tỉ lệ viêm 